\section{Trainee concerns regarding the Specialty Certificate Examination: results of a British Thoracic Society national survey}

As aspiring respiratory physicians are aware, The Federation of Royal Colleges of Physicians of the UK (FRCPUK) has introduced Specialty Certificate Examinations (SCEs) to complement workplace-based assessments. Successful completion of the SCE in Respiratory Medicine is a prerequisite for Certificate of Completion of Training for all UK respiratory trainees whose specialist training began during or after August 2007.

The SCE comprises two papers, each lasting $3 \mathrm{~h}$ and containing 100 questions in a 'best of five' format. Delivery and marking of the examination is computer-based. The FRCPUK has worked in partnership with specialist societies, including the British Thoracic Society (BTS), to optimise examination validity and reliability.

Analyses of SCE performance have been reported by the MRCP (UK) Central Office, ${ }^{1}$ but to date, there is little published data regarding the perceptions of trainees undertaking these examinations. ${ }^{2}{ }^{3}$ The BTS Specialist Trainees Advisory Group therefore undertook an anonymised electronic survey of all BTS trainee members to establish their views of the SCE in Respiratory Medicine. The total number of responders was 95 (response rate 14\%), of whom 56 (59\%) had undertaken the SCE. Perceptions were measured by Likert rating scale with an option for free text.

In this survey, the majority of trainees felt the SCE to be appropriate in difficulty, content and duration and the examination test centres to be acceptable for purpose. However, free text comments demonstrated strong feeling that the examination fee of $£ 861$ for UK candidates ( $£ 1081$ for overseas candidates) is not justified, particularly when fees for comparable professional examinations are significantly less ( $€ 280$ for the European Respiratory Society's European Diploma in Respiratory Medicine).

There is little transparency regarding costs to the FRCPUK of providing the 
SCE and understandable concern that trainees are paying in excess of 'cost price', potentially subsidising other activities of the FRCPUK.

Precedent exists that should act as a warning to the FRCPUK. The Royal College of Psychiatrists had to reduce and freeze examination fees (as well as subsidise trainee continued professional development), in response to concerns that the College 'made $£ 604000$ profit from membership examination fees in 2011'.

Lack of clarity regarding examination fees risks diminishing the relevance of the Respiratory SCE. While the SCE is mandatory for UK trainees, overseas candidates are likely to seek alternative, lower cost specialty examinations. Furthermore, UK respiratory trainees may elect to follow the example of UK cardiology trainees, who sit European examinations with UK diets instead of a dedicated SCE.

Delegates at the British Medical Association Junior Doctors' Conference last year passed a motion calling for all Royal Colleges to be transparent in their use of income raised by examination fees. In response to the concerns of our members, the BTS Specialist Trainees Advisory Group is calling for greater transparency from the FRCPUK regarding the examination fees for the SCE in Respiratory Medicine. Overall, we concur with the opinion of Dr John Cookson that 'the publication of robust costings (for the SCE) would be a service to all of us'.

Caroline Marie Patterson, ${ }^{1}$ Richard lan Carter, ${ }^{2}$ James William Dodd, ${ }^{3}$ Andrea Collins ${ }^{4}$

${ }^{1}$ CLAHRC, Imperial College, Chelsea and Westminster

Campus, London, UK

${ }^{2}$ Centre for Translational Inflammation Research, University of Birmingham, Birmingham, UK ${ }^{3}$ Department of Academic Respiratory Medicine, University of Bristol, Bristol UK

${ }^{4}$ Respiratory Infection Group, Liverpool School of Tropical Medicine, Liverpool, UK

Correspondence to Dr Caroline Marie Patterson, CLAHRC, Imperial College, Chelsea and Westminster Campus, 369 Fulham Road, London SW10 9NH, UK; cmpatterson@doctors.net.uk

Acknowledgements Acknowledgements are extended to Shelia Edwards (Chief Executive of the BTS) and all members of the BTS Specialist Trainees Advisory Committee for their support and guidance.

Contributors CMP devised the electronic survey with AC, and collated the results. CMP, RIC and JWD contributed to data interpretation. CMP, RIC and JWD wrote the manuscript and CMP acts as guarantor for the submission.

Competing interests None.

Provenance and peer review Not commissioned; internally peer reviewed.

To cite Patterson CM, Carter RI, Dodd JW, et al. Thorax 2014;69:85-86.

Received 5 August 2013

Accepted 7 August 2013

Published Online First 23 August 2013

Thorax 2014:69:85-86.

doi:10.1136/thoraxjn-2013-204306

\section{REFERENCES}

1 The Specialist: Newsletter of the Specialty Certificate Examinations. MRCP (UK) [Internet]. Dec 2011. http:// www.rcpe.ac.uk/exams/downloads/specialist-dec-2011. pdf

2 Medford A, Jeyabalan A. Respiratory specialty specific examinations in the south west. Clin Med 2012;12:609.

3 Goenka N, Wilmot E, Shaw K. Preparing for the specialty certificate examination. Pract Diab Int 2011;28:9.

4 Jaques H. Royal College of Psychiatrists offers free CPD in response to fee surplus. BMJ Careers [Internet]. 07 Jul 2013. http://careers.bmj.com/careers/ advice/view-article.html?id=20010963

5 Mucklow J, Dacre J. A critique of the specialty certificate examinations of the Federation of Royal Colleges of Physicians of the U.K. Clin Med 2010;10:519-20; author reply 20. 